\title{
Construction of an electronic place by students and what they might be learning
}

\author{
J. Cockeram \\ School of Architecture and Planning, \\ National Institute of Creative Arts and Industries, \\ University of Auckland, New Zealand
}

\begin{abstract}
Nonsense building is, I believe, what we are all engaged in, with and by. I am using the word nonsense to indicate two meanings of what might be being learned. The first is in the Victorian nonsense writing of not completely understood sentences and the second to mean that it doesn't make sense to me. This is an argument from the subjective point of view. It looks at the computing work done by a group of mid education students in the Architecture School, University of Auckland, in New Zealand. The intuitive learning of an architect is one of the reasons the education takes five years. We keep them going over and over things till they get an automatic response they can't identify as having been thought about. They come to a place they just know about and they (fingers crossed) are articulate about it. This contextual value of about right will be analysed as the place of discovery of the unknown elements of Architecture. The computer is enabling students to visualise but also it starts them to see the way in which the information contained in the database of the 3D model leads to other ways of using, and translating the information. These ways include shifting the information to another machine and its language.

The work also covers finding out what is available in our kiwi culture to build, create and generate Architecture. Sight, sound, colour and the on going bilingual exchanges between the work of shadows, drawings and the work of light, computing are programming the students of Architecture. The unseen defaults, the greys of gloominess, and the brilliant response and reaction of the high contrast values or broad tonal values, are all influencing the aesthetics, as a sensual perception, of current architectural practise.
\end{abstract}

Keywords: computing, thinking, designing, environmental stimulation, talking. 


\section{Introduction}

The work done for the paper ARCHDRC308 was offered for the first time this year (2006). The paper came at the start of the third year for most of the Architecture students. It was the first five weeks of ten weeks of delivered lectures. Five about computing and five about drawing, but the paper sits for these students in a line of papers that started with a set of twelve lectures in computing and twelve in drawing, for two years, so a total of forty-eight hours of lectures over two years. It was an opportunity to try something different as this group has done more computing than we will have again.

What I decided to try to do was get the students to see the board use of the computer in the construction of the Architecture they are interested in. It was a time for them to break out of the internalised world of the computer and get them to see the large number of small interfaces in the dynamic world of Architecture computing.

The work requested was getting them to step into talking and emailing people who are the culture, the people of the construction industry of Auckland and the world.

What happened was interesting as the different ways of thinking that were shown in the different approaches. Each group was either two or three people, but no two results were the same. The work generated was a flash file or a PowerPoint presentation that the students showed first to the class and then after a commentary they handed in the finished product that had to contain a number of things including a construction timetable and a costing of the pieces required to make the installation into the building.

\subsection{Trial and error}

But let's go back to my abstract. In the last paragraph I wrote;

Sight, sound, colour and the on going bi-lingual exchanges between the work of shadows, drawings and the work of light, computing are programming the students of Architecture. The unseen defaults, the greys of gloominess, and the brilliant response and reaction of the high contrast values or broad tonal values, are all influencing the aesthetics, as a sensual perception, of current architectural practise.

And I want to acknowledge research into the early child hood development, into learning, into the blending of cultures, into the work done, for caring into the work helping change peoples, lives into pattern recognition, into observation and start saying to you that the value of good is tied into the mediation of my body at a chemical , biological, and behavioural level. (I always worry that I am not yet seeing the complete me or them and that I might miss something, but that is always the condition.)

So Trial and Error. I choose this because it is part of the mechanisms of evolution. In a time where the possibility is that we are not evolving as we have in the past perhaps because we have, must have, mediated our environment in some very distant past. I think of getting out of the wind as an indicator of a 
process of evolution that is trying to achieve comfort but I think of wrapping up warm as a result of human mediation of the environment to achieve comfort, but those lines are something to be developed else where. Here I want to think of the mediated environment as being the place of exchange between educator, student and computer as well as the situation in which they sit, or stand.

So I think of trail and error and chuckle about the fact that the belief structures being generated around the computer in artistic and scientific endeavours are that if you make a mistake, it won't work. If we think about it we know (and therefore don't know) that it is our mistakes, it is our assumptions followed by things that disprove our assumptions that trigger us into changing our behaviours that trigger us into developing a new method of contending.

We fix the error by trailing new methods. We handle the situation by trying and learning. We eventually learn, are programmed by our choices. So the programming is triggered by our environment, internal or external, and we, not some raving lunatic, are choosing our programme, although the testosterone levels do play a part in the education of most architects.

\section{The methodological approach}

Nonsense building is, I believe, what we are all engaged in, with and by. I am using the word nonsense to indicate two meaning of what might be being learned. One as in the Victorian nonsense writing of not completely being understood, or in this case not completely understanding meanings, held by the student after engaging with the activity we have given them. Here in this work we end up with narratives, poems and lines of thinking that getting us thinking. If we look for ideal or 'correct' answers, we will find frustration in ourselves, but in the students we will see thinking shown in a couple of ways.

First: "the let's throw this together as fast as we can because life has been great and I don't care about this assignment." A valid response and one which we need to accept and provide a default answer. The answer that we show them. In this particular case it also ended up being one of the best. This answer being shown is interesting because often in Auckland New Zealand in my teaching they choose to rebel much in the way students don't read the books you recommend or resist until the last moment, often it is done in a really simple way with not much thought is given by the student to the assignment.

Second: the "Cool the computer can do anything and so can I, so, let's try to do everything." This can produce very good results but is fraught with problems when people don't quiet get there, when pieces are missing because the story, the line of thinking is yet to be completed.

Third: the "Tell me what to do and I'll do it." This is the most dangerous of all for creativity and therefore for the generation of "star" architects. It is still valid but it is part of the group, part of community generated Architecture... (and again here is a line of thinking for another time.)

Fourth: the "I will just do what you say because you know and I don't." this is the one that frustrates me most and it is because just like just, it indicates a devaluing of the work by the student and more problematically it indicates a 
shutting down of the thinking about the issue, in favour of someone else's thinking. And yet I know this to be an important part of the multiple centred design approach learning not to hold on to tightly to something which is not important, really... (and again here is a line of thinking for another time.)

And I am sure I could find many more. I recognise many blends much like wine or scotch. You can blend and mix 50\% this $45 \%$ that, and the final 5 might be the washing of a strange barrel or the gem of a moment.

Two: in the it doesn't make sense to me. A colleague told me after forty you can't talk to students, they just don't "get" you. Charles Walker eminent academic and architect suggested that we move with our friends into a position of old people. Really very useful in some ways and entirely problematic in other ways, useful because for some students they will believe you because you have been here long enough and problematic because the others will just say what do you know and the answer they will find for themselves. The hope is that in all that work somehow we manage to get something to stick, if not in the conscious mind at least as a pattern in the subconscious mind. And the metaphor here is the lolly scramble. We throw things up into the air, and with some luck, we then are able to watch a few people get the lollies and savour the sweetness. We are able to then watch the frustrated circle around say that they didn't want it anyway. Those beyond that have the "ah I didn't try for it" and those who seem further away are engaged, watching and observing. The observation sits and may be committed with the assistance of mirror neurons to memory or not. Brainwashing and education of the architect, of any profession, are all similar. Both seem to wish for us to put our health at risk, to not sleep enough to eat badly to abuse ourselves in ways we wouldn't allow others to or we would insist on in the 'if I did it this way you will do it the same way'.

This is an argument from the subjective point of view. The identification of the types of subjective points of view are caught in a behaviourist issue of how do I know, of how do I find out, when I know of the flaws in perception and interpretation.

In a methodology, it is necessary to work out a likely response, which I did and was of course wrong. Again, the nonsense of research and learning is what we are dealing with. Remember I am using the word nonsense to indicate the level of learning/understanding that the participants had before the project was started.

The students and I had three lectures to look at the work done in Kolarevic, B. and Malkawi, A. (2004) Performative architecture: beyond instrumentality, Spon Press, New York. To look at the New Modernists, Folds, Blobs and Boxes. The DVD is produced and directed by Michael Blackwood but the thinking is lead and directed by the interviewer Joseph Rosa. Diller and Scofidio in Aberrant Architectures. Another DVD and the third DVD is not it is a video with architects talking about Reimagining Manhattan after September 11.

I want to credit the thinking but it gets very difficult. In a book the author is the king pin but in the collaborative effort who do I credit..

The final result handed in for marking I understand even less. But in this the subjective point of view, I am looking for things, parameters and the 
interrelationship between the variables with in the project. A consideration of how do I tell. What do I tell. What is enough information, what is too much information. What I want them to do is to make a positive conscious choice, for me, so yes it is tailored to me. I don't want them to do exactly what I have done, it is not possible for them to as in six hours and the previous two years we haven't given them enough time to rote learn ways, what I believe we must do is show and model behaviours. And get them to draw and map enough ideas, concepts and lines to appropriate help. Some will get the sweet of the lolly scramble and some wont but they will react in the range of ways. I don't want it, I didn't try and I was just looking. But with a bit of luck they were there and they did see and they therefore did get something more than just a nap.

\section{Theoretical approach}

\subsection{Two lines of thinking: my nonsense}

\subsubsection{About the learning}

In learning we start with the situation of very broken fields of knowledge in both the educator and the student. Partial knowledge is used to find similar positions and then to start discussing the possible implications of that in the chosen field.

This is the same mechanism that generates culture. In learning we instruct and coax a student into believing what it is we believe. In most cases we are working from the knowledge and interpretations of others. We very rarely get to engage in knowledge formation. In a philosophical argument it is not possible even when we see or hear the actuality of the experimental result because always we are engaged in the act of interpretation. What our eyes or ears deliver is only understood because we are train in the interpretation necessary. The world was flat when judged by experience but when knowledge of travelling around it became commonplace the world was a sphere in space. Not until the abstract implications of the world not being the centre of the world were we able to understand the implications of planets, wanderers and therefore start building a knowledge of our solar system.

\subsubsection{About culture}

In culture we build as suggested by Bhabha's theory of cultural hybridity and attempt to understand connections that have not been seen in global and colonial ideas. This pattern of understanding and re-discussing is, I believe, with in the nature of culture, and as Architecture has come to understand the computer in Architecture. It has seen a cultivation of interesting change in the ascetics used in the field. It is also the pattern that creates the possible understandings of reactive or a need for haptic responses in Architecture.

Architects need to be are different when they leave schools, but one generation is always different to the next. The architecture industry is different as a global phenomenon and different as a local manifestation. The built form of Architecture is different. The dreamed version is different. In New Zealand, we train roughly 200 graduates a year who are headed near and far. When our 
students look for exciting culture it is not found in the buildings they see. Rather it is in the nightclubs and that is might well be "house" in a building. The experience of joy is in experimentation in social placement but it would seem not in building. The building is not generated by the testing and free form possibilities of a computer or digital world. The building culture in New Zealand is one of timber buildings with just a few metal-framed buildings and in most cases, most architects are dealing with housing, or the domestic. At this scale of the culture of New Zealand, it is shown in the house.

\subsubsection{So that is about three (at least)}

So what happens when we ask for a students to go and find ways of using the computer in the Architecture they are currently dreaming of. They come back with many ways of 'building in' an interactive moment. In most cases they find ways of building clever or smart but conventional floors or walls. In this mideducation exercise, they are still conventional or are already imbibed to our way of thinking in our, their culture.

Next time I do this paper it will require that the students cite an example that they site a building from previous example, that they look further away and I need to find and show images of boats, surf boards, and any 'other' building tradition. In New Zealand we are privileged to have many cultures. So we could point to the tukutuku weaving of walls from Maoridom, the paper wall traditions of Japan, or to the steel and concrete of the Hawkesbay, to the lighter traditions of buildings in the warmth of the north and the rapo and stone building possibilities in the south. Some how I must get across that we have a lot in New Zealand besides the DIY, building in timber and gib.

\section{Changing conventions}

\subsection{Dreaming}

So how do we change the conventions of a small country? I have dream, a dream of never seeing the grey architecture image. The image generated by default light in the environment. I know that I will in 20years be teaching the same things of perception and subtractive and additive colour but I hope in 20 years the students I am currently teaching won't be accepting default lighting of a CAD package as satisfactory. That we will be playing with the biggest difference the computer offers. The light of the computer rather than the shadow of the drawing. That maybe, just maybe, the students will start to see the drawing conventions are wonderful but when working with the computer they need to think about that medium of light. Anyway this is a digression, but it points to how over the next couple of decades I will be attempting to change the desires of students by showing them that the rest of the world is fully engaged in the digital worlds of new materials and new methodologies and really it is just the same old stuff of form, light and human perception that we use when designing. I will be doing no more or less than giving them the opportunity to take up the issues of their culture and work in ways that reflect and modify their culture. 


\subsection{What is new}

Bhabha talks about how 'new' enters into our cultures. He types into the descriptions the notion that the blending of other and colonial or in our case that the blending of the draw and hand as being colonised by the digital production and screen, happens because "of the struggle of translation in the name of modernity? How do we catachrestically seize the genealogy of modernity and open it to the postcolonial translation? The 'value' of modernity is not located, a pirori, in the passive fact of an epochal event or idea - of progress, civility, the law - but has to be negotiated within the 'enunciative' present of the discourse". pg 242

So to interrupt this for students I would say Bhabha tells us to talk about things, cringing as I did so and hoping the geist is enough. That we need to speak draw or write and we now can add compute is not silly but does place the architecture in a place where it will be misjudged, misunderstood and it will misbehave. In this place of nonsense of partial knowledge, it will leave not new but retranslated and reinterpreted, new to us this time. This contextual values of about right, it sort of means, is the place of discovery of the unknown elements of Architecture in and of the "she'll be right culture".

"The new or the contemporary appear through the splitting of modernity as an event and enunciation, the epochal and the everyday. Modernity as a sign of the present emerges in that process of splitting, that lag, that gives the practise of everyday life its consistency as being contemporary. It is because the present has the value of a 'sign' that modernity is iterative; a continual questioning of the conditions of existence; making problematic its own discourse not simply as ideas "but as the positions and status of the locus of social utterance." pg 242

So Social Utterances are important. In the crits we give, in the seminars we require, our architects are learning to coax cajole and teach us, now and then they will coax cajole and teach clients.

The students of Architecture need to know that their Architecture will sit and utter the positions the status the locus of culture, they are running at the moment and need to engage more with the histories and ideas and methods and in so doing reconstruct themselves.

“... the projective but ideal speech community that is rescued within modernity by Habermas in his concept of communicative reason that is expressed in its pragmatic logic or argument and a 'decentred' understanding of the world: what we encounter in all these accounts are the proposals for what is considered to be essential gesture of Western modernity, an ethics of self construction' ...

I want to ask whether this synchronous constancy of reconstruction and reinvention of the subject does assume a cultural temporality that may not be universalist in its epistemological moment of judgement, but may, indeed, be ethnocentric in its construction of cultural 'difference'." pg 240

And to what ethnicity am I thinking, to one which is already tied and caught in the pluralistic understanding of Auckland's current student culture. I am 
pointing to a period that is not only physical aging but is exposure to ideas and is also innate curiosity and activity. That the ethos is the blend of the wine and is this gem or washing of the barrel, is this sweetness of the lolly or the watching of the game? And find myself restablishing requestioning in a construction of my own identity, ever caught in this debate of "who are you, so therefore I am?" That evolved sense of self-discovery, which is about position, about a reading of social utterances and a judgement and a valuing of worth. What ever we discover about the world is also about us. The 'you don't like' statement and the 'you like' statement are very important to the majority of our estrogen influenced students because they are environment readers and without the assurity or confidence of tesrtone the object obsession shifts in its focus.

The students who find themselves at the top of the grades in Architecture will I hope get a really bad, opps no dud(?) (trying to find the social and the least judgemental word.) so they are able to practise the 'let it go' when they get something not to their liking, be it bad or good, because we don't know what they think or want, in most cases.

And what does this have to do with the places of information delivery in/on a computer. Lots and absolutely nothing, except that in a learning institution the person who sits at the computer is what I, as an educator, have been watching and wondering how do we teach you. We don't they learn from the things they choose. What the motivation is for why they are doing what they are doing is only knowable by me because humans as individuals are never the same, but humans as individuated members of the collection start to group in statistical ways so the behaviours I see are possible but not assured. The only way of judging the individual is in some form of social utterance, paper, test, lecture, model, and or book, What the machine has made resource possible is the private learning and the private testing that the University believes. The computer machine is digital but is simply another form of information exchange. The web, the email, the TV, the digital are techniques not answers. The content in that utterance of a student is judged, is placed by both sides of the utterance exchange, whether the two sides are visible or not, whether they share the same values.

The computer is a poor subset of our lives, is a poor collection of information, but it is a great testing environment. It is not an object or tool for a lot of us. It is a $3 \mathrm{D}$ place and as the web seems to be returning to $2 \mathrm{D}$ delivery of information I hold on to the hope that we, particularly the architects, will "get" that the ability to think in $3 \mathrm{D}$ is what makes the difference.

\section{The work itself}

The sight, sound, colour and the on going bi-lingual exchanges between the work of shadows, drawings and the work of light, computing is immersing the students of Architecture in a world that satisfies the evolved needs of their perception system. It is this satisfaction that is problematic, good enough is not enough when it comes to a value laden judgemental laden thing like architecture. What we require of our students is the activity that is embedded within this argument. 
We require that students work with "the present (which) has the value of a 'sign' that modernity is iterative; (it is) a continual questioning of the conditions of existence; making problematic its own discourse"

(So have they and do they? Please continue judging and valuing them yourselves as they appear and disappear.)

While you do that let me continue to carry on. The nonsense we see being built by students who are looking out into the building culture is interesting as it shows at least two things. One is the strange result of not seeing things that looked like the Architectural moments portrayed in the New Modernists folds blobs and boxes. Or in the text Performance Architecture. Beyond instrumentality edited by Branko Kolarevic and Ali M. Malkawi. And two the control freak stuff, raising itself in the chance to react with a building.

In most cases there was no meaning put up with the work. There was just the sense of fun that be had with the Architecture. And the child in me likes that it might simply be fun but the architect within is pretty sure that the moment that the architect is not telling but reacts will have layered across it many meanings by people who currently still hunt for the thing that the environment tells them.

It is not at the conscious level it may not be subconscious or preconscious but it is the same value and judgemental thing we evolved to decode the world we live in. The reading, cognitive, Freudian or otherwise I leave to others, it is just that what we see is that learning is lifelong, the development rearrangement is life long and the accumulation and discernment and refinement is life long. What I think I am now seeing is a shift to where our students will learn. Because as I typed in a email the other day it is not the mechanisms is not the feeling of the pencil it is not the feeling of the card it is not the flashing of the light it is not the movement of flight. It is the insight that students get and then it is the cleverness in which they deliver that to someone else.

The work also covers finding out what is available in our kiwi culture to build, create and generate Architecture. And I would have thought the boat building of the yatch mad city of sails would have meant the fibreglass or wooden ribs or the sails would have featured but they didn't. It was however the technology of the interactive moment that was picked up. It was of the information handling that they were interested in, perhaps a modelling of themselves as they hunt for the information but I think it is a significant change rippling across our cultures, or may be they saw through me. This shift in interest is difficult. It is difficult because in Architecture we have used the mechanistic as a simple technology based way of giving value to Architecture. Is this interactive reactive moment in Architecture simply a 'new' problematic value? Architecture in its own time scale of $25,30,50$ or 100 years allows us to think slowly. The computer allows us to communicate quickly, sometimes.

What has been interesting is the shifting of information to another machine and those languages to the small digital conversational like programmes of control. Most popular would have been the switching generated by picking up information and the reaction or response of a control programme as shown by the interactive wall or ceiling. 
As a maker I work nights because it allows me to suspend my thinking and trust my creativity, those accidental triggers flowing in the brain.(think solenoid or induced flow in wires) As a writer I write when my brain is fresh and so able to analyse, after sleep, in the morning when with concentration it is possible to stop listening and write what it is. But behaviour changes and life intervenes so sometimes we just have to do what we have to do, change our minds therefore change our behaviour which others can then mis-interrupt as they see fit, or should that be to fit.

The argument can only be subjective until it is shared when it might become objective.

The construction of an electronic place by students and what they might be learning can not be known can only be misjudged unless they choose to engage in the social utterance.

\section{References}

[1] Bhabha, Homi K., The Location of Culture, Routledge: London; New York, 2004.

[2] Bhabha, Homi K., The Location of Culture, Routledge: London ; New York, 1994.

[3] Kolarevic, B., Malkawi, A., (eds.) Performative architecture: beyond instrumentality. Spon Press: New York. 2004.

[4] Melser, Derek, The Act of Thinking. MIT Press, Cambridge, Mass. 2004.

[5] The new modernists: Folds, blobs \& boxes [video recording]: [architecture in the digital era], Michael Blackwood, Michael Blackwood Productions: New York, 2004, [c2001].

[6] After September 11th [video recording]: [reimagining Manhattan's downtown.] Northvale, NJ: Audio Plus Video: New York, c2002.

[7] Aberrant architectures? [video recording] : [Diller \& Scofidio at the Whitney Museum.] Michael Blackwood Productions: New York, 2004, [c2003]. 